\title{
Melanins in fungi: Types, localization and putative biological roles
}

\author{
Andrea Vanesa Toledo a , Mario Emilio Ernesto Franco a , Silvina Marianela Yanil Lopez a , \\ María Inés Troncozo ${ }^{\mathrm{b}}$, Mario Carlos Nazareno Saparrat ${ }^{\mathrm{b}, \mathrm{c}, \mathrm{d}}$, Pedro Alberto Balatti ${ }^{\mathrm{a}, \mathrm{b}}$, *' \\ a Centro de Investigaciones de Fitopatología CIDEFI (UNLP-CICBA), Argentina \\ ${ }^{\mathrm{b}}$ Curso de Microbiología Agrícola, Facultad de Ciencias Agrarias y Forestales, UNLP, Argentina \\ ${ }^{\mathrm{c}}$ Instituto de Fisiología Vegetal INFIVE (UNLP-CONICET), Argentina \\ d Instituto Spegazzini, Facultad de Ciencias Naturales y Museo, Universidad Nacional de La Plata, Argentina
}

\section{A R T I C L E I N F O}

\section{Article history:}

Received 2 January 2017

Received in revised form

6 April 2017

Accepted 6 April 2017

Available online 8 April 2017

\section{Keywords:}

Melanins-stress-wall deposition-synthesis

\begin{abstract}
A B S T R A C T
Melanin is a secondary metabolite made up by complex heterogeneous polymers. Several classes of fungal melanins have been described like $\gamma$-glutaminyl-3,4-dihydroxy-benzene (GDHB)-, L-DOPA(eumelanin), DHN-, catechol-melanin, pyomelanin, $p$-aminophenol (PAP)-melanin, heterogeneous melanins as well as two others based on 5-deoxybostrycoidin and aspulvinone E. They have been mostly localized in cell walls of different structures of fungi, which suggest that they play a different biological role. They have been related mostly with morphogenesis, stress resistance, virulence and energy transduction. However, an enormous amount of work remains to be done to clarify, among other things, the role melanins play in fungi.
\end{abstract}

() 2017 Elsevier Ltd. All rights reserved.

\section{Contents}

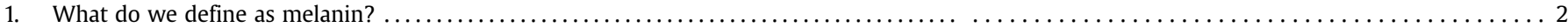

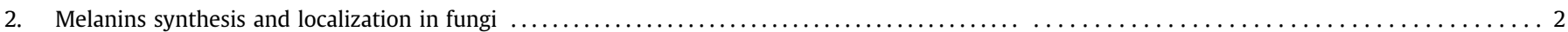



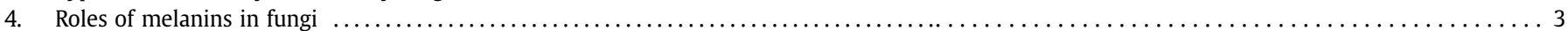



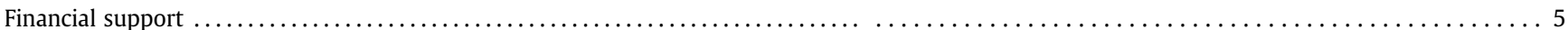

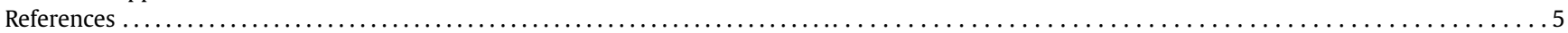

\section{What do we define as melanin?}

Melanins are secondary metabolites made up of complex heterogeneous polymers of phenolic and/or indolic monomers. Recently, nuclear magnetic resonance (NMR) studies showed that melanins area network of aliphatic and aromatic structures. Also, Sun et al. [1] by 2D-NMR spectroscopy and ${ }^{1} \mathrm{H}_{-}{ }^{13} \mathrm{C}$ heteronuclear single quantum correlation (HSQC), found in the crude extracellular melanin of Auricularia auricula, signals of both aliphatic and aromatic structures. Therefore the condensed molecular formula of

* Corresponding author. CIDEFI, Facultad de Ciencias Agrarias y Forestales, Universidad Nacional de La Plata, Calle 60 y 119 La Plata (1900), Argentina.

E-mail address: pbalatti@gmail.com (P.A. Balatti). melanin might be $\left[\mathrm{C}_{18}(\mathrm{OR}){ }_{3} \mathrm{H}_{7} \mathrm{O}_{4} \mathrm{~N}_{2}\right]_{\mathrm{n}}$.

\section{Melanins synthesis and localization in fungi}

Melanins structure increases in complexity as fungal cultures grew older. These pigments have carbon-containing covalent linkages between aromatics and either chitin-derived $N$-acetylglucosamines or membrane glycerides. Solid-state NMR data of the melanin of Cryptococcus neoformans support a stacking of indolbased aromatic structures through covalent cross-linkages, a material that is ordered at microsites but globally amorphous [2]. Recently, Beltrán-García et al. [3] reported that the melanin isolated and purified from the mycelium of Mycosphaerella fijiensis is constituted by 50 units of 1,8-dihydroxynaphthalene (DHN). Since 
there is a lack of knowledge regarding the structure of other types of melanins additional studies should be performed in order to know more about their structure. Further analysis, using solid-state NMR and physical/imaging techniques, should provide the bases to characterize the pigment architecture in the cell wall, which will be useful to disregard artifacts derived from the harsh chemical treatments that are frequently used to extract DHN-melanin.

Frequently, soluble melanins such as pyomelanin and heterogeneous melanins as well as insoluble ones, mostly immobilized in the cell wall, also are released in culture supernatants. In Candida albicans and Cryptococcus neoformans melanins are extruded that seems to occur through a complex set of events that include vesicle-like structures that are free or often loosely bound to the cell wall exterior $[2,4]$. However, melanins deposition and localization in the cell wall of fungi vary within species, with culture conditions and/or the structures differentiated by each fungus [4]. This basically suggests that in fungi melanin might be playing more than just one biological role. Future studies should be aimed not only at understanding their biological role but also at clarifying the way melanins are secreted in other fungi.

While in some fungi melanin is part of a layer tightly associated to the plasma membrane on the inner side of the cell wall, like in the appressorium of Magnaporthe grisea, in other fungi like in Cryptococcus neoformans, it is deposited throughout the cell wall in the form of concentric rings. Alternatively melanin is deposited in the outermost layers such as in the hyphae of Pseudocercospora griseola or as granules on the surface of the walls of pseudohyphae and yeasts like Candida albicans [4-6].

Melanin is synthetized and secreted in specialized vesicles, occasionally denominated 'virulence bags', in an analogous way to the mammalian melanosomes [7]. In this way, the extracellular polymer is transported out of the cell and can be anchored to the wall. Therefore, most probably the environmental conditions as well as the metabolic activity of fungi might alter melanin synthesis and extrusion in different fungi.

Many fungi contain melanins in vegetative as well as reproductive structures such as those belonging to the dematiaceous fungi that are known as the brown-pigmented ones. Melanins such as1,8-DHN- and L-3,4-dihydroxyphenylalanine (L-DOPA)-ones have been mostly associated to ascomycetous and basidiomycetous ones, respectively. However, some representative fungi from both taxonomic groups (phyla), such as those of a genus, can synthetize different dark pigments. Furthermore in many cases they produce pigments in specific structures. In this sense, some fungi have the ability to synthetize a type of melanin according to the environmental conditions as well as the developmental stage (Table 1). The presence of melanins in fungi adapted to different environments and the fact that the same melanin is synthetized by a fungus, independently of the environmental conditions, suggests that this molecule plays different crucial biological roles in nature. However, more studies should be performed at identifying the role that different types of melanins play on biological processes.

\section{Types of melanins synthetized by fungi}

While many fungi synthetize melanins constitutively, others do so only under certain culture conditions and/or if specific precursors are available. While several fungi synthetize melanin endogenously via a DHN intermediate, others, like Tetraploa aristata [32], synthetize an undefined set of soluble black pigments that are known as heterogeneous melanins. They are produced by a mechanism of detoxification that is responsible of polymerization of phenolic compounds of various origins, including those present in fungal secretions, which are available outside the cell [33].

Based on their biochemical precursors, pathways and/or components several classes of fungal melanins have been described like $\gamma$-glutaminyl-3,4-dihydroxy-benzene (GDHB)-,L-DOPA-, which is known as eumelanin, DHN-, catechol-melanin, pyomelanin and p-aminophenol (PAP)-melanin as well as the heterogeneous melanins. Recently, two new melanins have been reported. One is located within the periderm of perithecia of representatives of the Fusarium graminearum group, it is based on 5-deoxybostrycoidin, which is synthetized from the reaction of anhydrofusarubin derivatives and ammonia [20]. The other one is Asp-melanin that is present in the wall of conidia of Aspergillus terreus. The precursor of this melanin, 4-hydroxyphenylpyruvate, is oxidized generating in this way aspulvinone E derivatives, which are polymerized [11].

Fungal melanins as well as those of plants are and have been known as allomelanins, an unclear term that include dark pigments synthesized from nitrogen-free precursors, such as those derived from catechol and DHN [34]. Furthermore, if pigment synthesis includes the incorporation of cysteine into their L-DOPA-derived structure, like in Auricularia auricula, they are known as pheomelanins [1]. Although the polyketide synthase pathway is involved in the synthesis of DHN-melanins, also phenoloxidases have been related to its synthesis as well as in DOPA-melanin (Fig. 1). Interestingly, disruption of genes of several melanin-pigmented fungi resulted in mutants that developed albino colonies in-vitro. When they were complemented with wild type genes, the pigmented phenotype was recovered. Furthermore, the melanin found in conidia of $A$. terreus is synthesized by a non-canonical pathway, which includes an unusual non-ribosomal peptide synthase-like enzyme and a tyrosinase [11]. This is a peculiarity considering that Aspergilli mostly synthetize DHN-melanin through a polyketide synthase derived naphtopyrone. So the enzymes and mechanisms involved in the different pathways of melanin synthesis still remain obscure (Fig. 1).

\section{Roles of melanins in fungi}

Fungal melanins are unique in that they play a myriad of biological roles, in morphogenesis, virulence, energy transduction and/or C storage. However, in fungi melanins are scavengers of stresses, protecting in this way cell viability, which does not seem to be the only role.

In terms of morphogenesis, melanin was found to be a key structural component of conidial wall of Aspergillus fumigatus. Also, it has been related to the expression of adhesins as well as other virulence factors [35], therefore it appears that in this case melanin plays a critical role, very early, just before infection occurred. In addition to this in Bipolaris sorokiniana melanin has been associated to the development of aerial hyphae and conidiogenesis [14], suggesting that they might play another role. So melanins might affect fungi very early as well as late along their life cycle.

Melanins are required by many fungi like plant, animal and human pathogens and because of this have been associated with virulence. The radical and chemical nature of melanins suggests that they might be working as a shield against hydrolytic enzymes that may affect fungal cell walls. In addition to this, melanins also might sequestrate host defensive proteins and metals, trap single electrons or act as a photoactivated 'toxin' that generate singlet molecular oxygen, which has been shown for the DHN-melanin of $M$. fijiensis. In several plant pathogens melanin plays a pivotal role in generating osmotic pressure within the appressorium, when hyphae penetrate plant cell walls, which was described for Magnaporthe and Colletotrichum species. In these pathogens, mutations aimed at inhibiting melanization led to a reduction in virulence.

Melanins enhance tolerance of fungi to environmental stresses, improving in this way their survival. Melanins protect fungal structures from UV radiation, temperature, oxidizing agents and 
Table 1

Type, localization and putative role of melanins in different fungi.

\begin{tabular}{|c|c|c|c|c|}
\hline Taxa* & Melanin type & Localization & Putative role & Reference \\
\hline \multirow{4}{*}{$\begin{array}{l}\text { Agaricus bisporus } \\
\quad \text { (Agaricaceae) }\end{array}$} & GHB- & Basidiospore wall & $?$ & \multirow[t]{4}{*}[8,9]{} \\
\hline & PAP- & $?$ & $?$ & \\
\hline & DOPA- & $?$ & $?$ & \\
\hline & Catechol- & $?$ & $?$ & \\
\hline \multirow{2}{*}{$\begin{array}{l}\text { Aspergillus terreus }^{\mathrm{a}} \\
\quad \text { (Trichocomaceae) }\end{array}$} & Asp- & Conidia & Tolerance to UV radiation and acidic environments and defence & \multirow[t]{2}{*}[10,11]{} \\
\hline & DHN- & Culture broth & from predation by amoeba & \\
\hline \multirow{3}{*}{$\begin{array}{l}\text { Auricularia auricula } \\
\qquad \text { (Auriculariaceae) }\end{array}$} & Pheomelanin & Fruiting bodies & $?$ & \multirow[t]{3}{*}[1,12,13]{} \\
\hline & DHN- & Fruiting bodies & $?$ & \\
\hline & Eumelanin-type & Extracellular medium & $?$ & \\
\hline $\begin{array}{l}\text { Bipolaris sorokiniana } \\
\quad \text { (Pleosporaceae) }\end{array}$ & DHN- & Wall in hyphae and conidia & Development, fitness and survival & {$[14,15]$} \\
\hline $\begin{array}{l}\text { Cenococcum geophilum } \\
\text { (Gloniaceae, } \\
\text { Mytilinidiales) }\end{array}$ & DHN- & Hyphae wall & Tolerance to water stress & {$[16,17]$} \\
\hline $\begin{array}{l}\text { Cladosporium } \\
\quad \text { cladosporioides }^{a} \\
\quad \text { (Cladosporiaceae) }\end{array}$ & $\begin{array}{l}\text { DHN-melanin like } \\
\text { compounds }\end{array}$ & Wall in hyphae and conidia & Tolerance to stresses imposed by fungicides or the environment & [18] \\
\hline $\begin{array}{l}\text { Cryptococcus neoformans } \\
\quad b \text { (Tremellaceae) }\end{array}$ & DOPA- (eumelanin) & Extracellular vesicles and cell wall & $\begin{array}{l}\text { Pathogenicity. Virulence factor. Protection against host defence } \\
\text { systems (immune effector cells, phagocytosis and oxidative injury) }\end{array}$ & {$[7,19]$} \\
\hline $\begin{array}{l}\text { Fusarium graminearum } \\
\quad \text { (Nectriaceae) }\end{array}$ & $\begin{array}{l}5- \\
\text { Deoxybostrycoidin- }\end{array}$ & Perithecial wall & Tolerance to UV radiation and reactive oxygen species & {$[20]$} \\
\hline $\begin{array}{l}\text { Metarhizium anisopliae } \\
\quad \text { (Clavicipitaceae) }\end{array}$ & DHN- & $?$ & $\begin{array}{l}\text { Virulence factor. Hydrophobic attraction, water absorption, } \\
\text { adhesion, conidia germination and tolerance to water and } \\
\text { oxidative stress }\end{array}$ & {$[21]$} \\
\hline $\begin{array}{l}\text { Monilinialaxa }^{\mathrm{a}} \\
\quad(\text { Sclerotiniaceae })\end{array}$ & DHN- & All structures differentiated & $\begin{array}{l}\text { Pathogenicity. Sporogenesis. Survival. Tolerance to environmental } \\
\text { stresses and autolysis }\end{array}$ & {$[22]$} \\
\hline Mucor spp. ${ }^{\mathrm{d}}$ (Mucorales) & $?$ & Outer wall of sporangiospores & $?$ & {$[23]$} \\
\hline $\begin{array}{l}\text { Neocallimastix sp. }{ }^{\mathrm{e}} \text { Isolate } \\
\text { MC-2 } \\
\text { (Neocallimastigaceae) }\end{array}$ & $?$ & Wall of mature resistant sporangia & Survival & {$[24]$} \\
\hline $\begin{array}{l}\text { Ophiocordyceps sinensis }{ }^{\mathrm{a}} \\
\quad \text { (Ophiocordycipitaceae) }\end{array}$ & DOPA- & $\begin{array}{l}\text { Fermentation broth of submerged } \\
\text { cultures }\end{array}$ & $?$ & [25] \\
\hline $\begin{array}{l}\text { Penicillium chrysogenum }{ }^{\mathrm{a}} \\
\quad \text { (Trichocomaceae) }\end{array}$ & Pyomelanin & Extracellular medium & Survival under nutrient and water stress & {$[26]$} \\
\hline $\begin{array}{l}\text { Pseudocercospora griseola } \\
\quad \text { (Mycosphaerellaceae) }\end{array}$ & DHN- & Wall in hyphae and conidia & Morphogenesis & {$[5,27]$} \\
\hline \multirow{3}{*}{$\begin{array}{l}\text { Sporothrix schenckii } \\
\quad \text { (Ophiostomataceae) }\end{array}$} & DHN- & Constitutively in conidial and yeast cells & Virulence related to infection and against phagocytosis & \multirow{3}{*}[28-30]{} \\
\hline & DOPA-(eumelanin) & $\begin{array}{l}\text { Wall of conidia, yeast cells, and hyphae if } \\
\text { L-DOPA is available during fungal growth }\end{array}$ & $\begin{array}{l}\text { Virulence related to infection and against phagocytosis. Protection } \\
\text { against antifungal drugs }\end{array}$ & \\
\hline & Pyomelanin & $\begin{array}{l}\text { Extracellular medium if L-tyrosine is } \\
\text { available during fungal growth }\end{array}$ & Quencher of oxidative stress. Protection against antifungal drugs & \\
\hline $\begin{array}{l}\text { Synchytrium endobioticum }{ }^{\mathrm{c}} \\
\text { (Synchytriaceae, } \\
\text { Chytridiales) }\end{array}$ & $\begin{array}{l}\text { Allomelanin like } \\
\text { compounds? }\end{array}$ & Resting spores & Survival & [31] \\
\hline
\end{tabular}

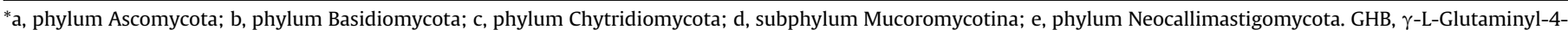
hydroxybenzene. PAP, p-Aminophenol. DOPA, L-3,4-dihydroxyphenylalanine. DHN, 1,8-dihydroxynaphthalene.

antibiotics [36]. Melanins might be playing the role of an extracellular redox buffer that can neutralize oxidants generated by environmental stresses. Furthermore, melanins protect fungi from solar radiation and UV light. In fact, pigments dissipate light energy either as heat or in chemical reactions or by scavenging active oxygen species, e.g. superoxide, and singlet oxygen, which result in the consumption of molecular oxygen. Therefore, melanin protects fungi against a broad range of environmental stresses as well as toxic molecules, improving in this way their survival ability. However, the protective role each melanin plays in nature is dependent on its synthesis pathway, its localization within cells as well as its behavior against an environmental stress. Just as an example, viability of $A$. terreus conidia within acidic environments has been related to the presence of the Asp-melanin in the wall, suggesting that the pigment plays an ecological role [11].

Melanized fungal cell walls are relatively resistant to decomposition; because of this melanins might be a source of storage $C$ in the soil. Organic matter derived from Cenococcum geophilum, which is drought tolerant and abundant in water-stressed habitats, may represent as much as $50 \%$ of organic C in soils [16]. Dark pigments like melanins might also function in energy transduction, which might enhance growth of melanized fungi also suggesting a role for capturing and utilizing energy [37].

The broad spectrum of functions fungal melanins play suggests that they might have several applications in medicine as well as in pharmacology, cosmetics and/or other fields [25]. The knowledge of the biosynthesis as well as the role melanins play in pathogenic fungi as well as the enzymes involved in melanization is crucial to design strategies to manage plant pathogens of crops.

\section{Final considerations}

Data regarding the structural organization of melanins in fungi, whether they are located in cell walls or elsewhere, including the extracellular medium, are scarce. Such studies have only been performed in Candida albicans and Cryptococcus neoformans, therefore there is no information regarding the mechanisms involved in melanization in other fungi. It is known that while some fungi synthetize one type of melanin, others synthetize two or three different ones. This suggests either that each one plays a different biological role or that their crucial role oblige organisms to have alternative biosynthetic pathways so that they are available. In 


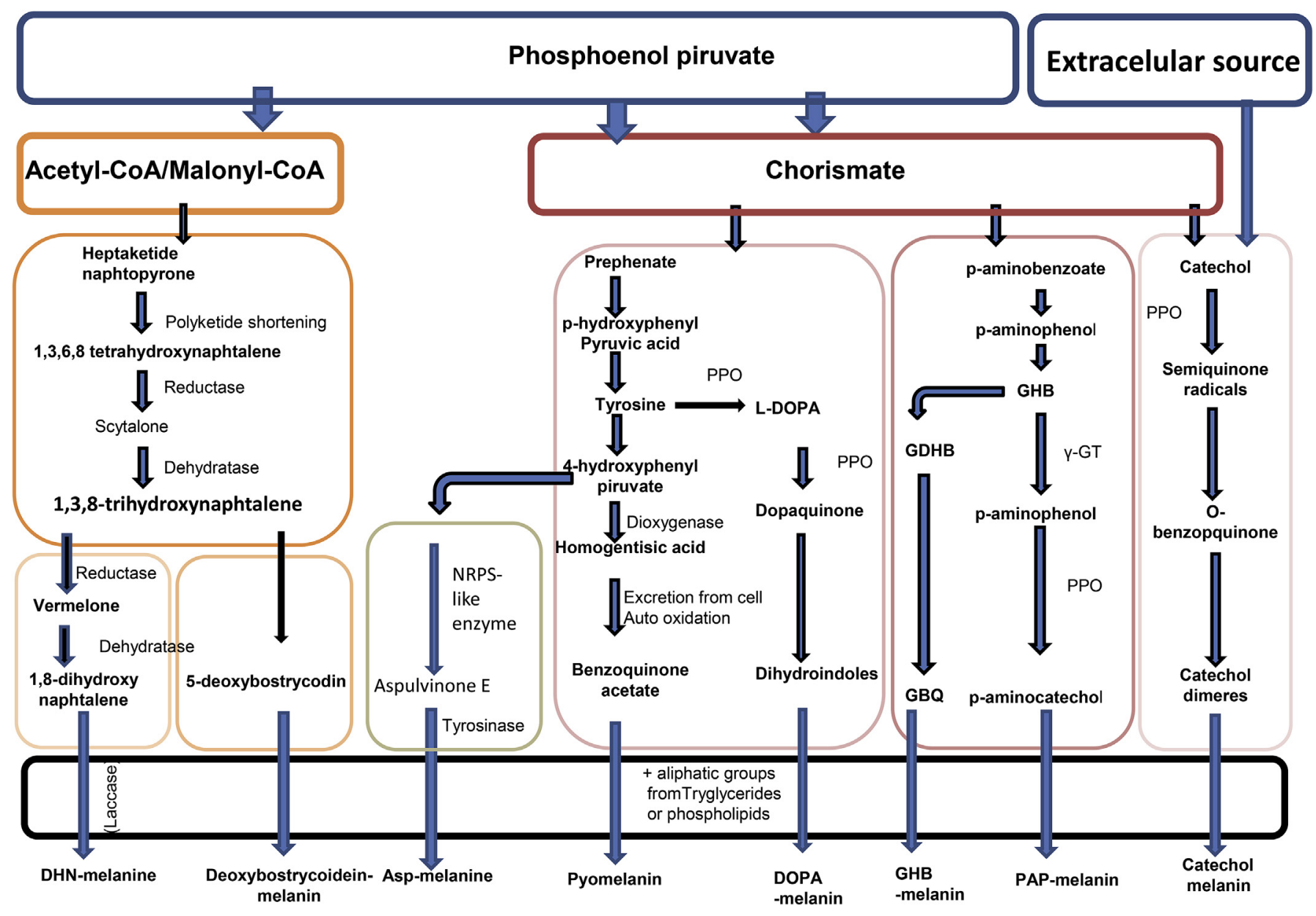


dihydroxybenzene. $\gamma$-GT, $\gamma$-Glutaminyltransferase. GBQ $\gamma$-L-glutaminyl-3,4-benzoquinone. NRPS, non-ribosomal peptide synthase.

line with this, Frandsen et al. [20] found that in Fusarium pigmentation is sustained by conservation, replacement and development of redundant pigments. However, different melanins have been found in fungal structures, which can be additionally altered by the environment that also might differentially regulate their synthesis. All this together strongly suggests that melanins play several crucial roles in fungi mostly related with survival and also that each type probably plays a specific biological role.

It is also important to consider that the same melanins are present in phylogenetically unrelated fungi as well as functionally diverse groups. As mentioned before this suggests that melanins play a similar function in diverse fungi and help all of them to cope with the stresses imposed by each environment. Also the fact that some fungi synthetize more than one melanin suggest either that each of them plays a different biological role quenching the effect of different damaging agents or that they are so important for survival of fungi that they synthetized more than just one type of them.

Additional studies should be performed aimed at clarifying the synthesis and role these pigments play in fungi such as in representatives of the Mucoraceae, Neocallimastigaceae and Synchytriaceae, which should be easier considering the availability of genomes of related fungi. This will allow performing a comparative analysis of genes coding for the enzymes involved in melanin synthesis as well as their expression levels under different environmental conditions. This should also be a complement with site directed mutations that together with phenotype evaluation and complementation studies will allow researchers to elucidate the specific role each type of melanin play in fungi. These lines of research are obvious but even though researchers are aware of the importance of melanins in nature, their role in fungal biology remain unknown.

\section{Financial support}

This work was supported by PICT 2012-2760 and PICT 20151620 ANPCyT and grants provided by Comisión de Investigaciones Científicas de la Provincia de Buenos Aires and the Universidad Nacional de La Plata. AT and MCNS are researchers of Consejo Nacional de Investigaciones Científicas y Técnicas (CONICET). MEEF and SMYL are fellows of CONICET. MIT is a fellow of the Universidad Nacional de La Plata. PAB is a researcher of the Comisión de Investigaciones Científicas de la Provincia de Buenos Aires (CICBA).

\section{References}

[1] S. Sun, X. Zhang, S. Sun, L. Zhang, S. Shan, H. Zhu, Production of natural melanin by Auricularia auricula and study on its molecular structure, Food Chem. 190 (2016) 801-807.

[2] J.D. Nosanchuk, R.E. Starkand, A. Casadevall, Fungal melanin: what do we know about structure? Front. Microbiol. 6 (2015) 1463.

[3] M.J. Beltrán-García, F.M. Prado, M.S. Oliveira, D. Ortiz-Mendoza, A.C. Scalfo, A. Pessoa Jr., M.H.G. Medeiros, J.F. White, P. Di Mascio, Singlet molecular oxygen generation by light-activated DHN-melanin of the fungal pathogen Mycosphaerella fijiensis in Black Sigatoka Disease of Bananas, PloS One 9 (2014) e91616. 
[4] C.A. Walker, B.L. Gómez, H.M. Mora-Montes, K.S. Mackenzie, C.A. Munro, A.J.P. Brown, N.A.R. Gow, C.C. Kibbler, F.C. Odds, Melanin externalization in Candida albicans depends on cell wall chitin structures, Eukaryot. Cell 9 (2010) 1329-1342.

[5] A. Bárcena, G. Petroselli, S.M. Velasquez, J.M. Estévez, R. Erra-Balsells, P.A. Balatti, M.C.N. Saparrat, Response of the fungus Pseudocercospora griseola f. mesoamericana to Tricyclazole, Mycol. Prog. 14 (2015) 76.

[6] P. Mandal, T.S. Roy, T.K. Das, U. Banerjee, I. Xess, J.D. Nosanchuk, Differences in the cell wall architecture of melanin lacking and melanin producing Cryptococcus neoformans clinical isolates from India: an electron microscopic study, Braz. J. Microbiol. 38 (2007) 662-666.

[7] M.L. Rodrigues, E.S. Nakayasu, I.C. Almeida, L. Nimrichter, The impact of proteomics on the understanding of functions and biogenesis of fungal extracellular vesicle, J. Proteomics 97 (2014) 177-186.

[8] M.J. Butler, A.W. Day, Fungal melanins: a review, Can. J. Microbiol. 44 (1998) $1115-1136$.

[9] A. Weijn, S. Bastiaan-Net, H.J. Wichers, J.J. Mes, Melanin biosynthesis pathway in Agaricus bisporus mushrooms, Fungal Genet. Biol. 55 (2013) 42-53.

[10] A.K. Pal, D.U. Gajjar, A.R. Vasavada, DOPA and DHN pathway orchestrate melanin synthesis in Aspergillus species, Med. Mycol. 52 (2014) 10-18.

[11] E. Geib, M. Gressler, I. Viediernikova, F. Hillmann, I.D. Jacobsen, S. Nietzsche, C. Hertweck, M. Brock, A non-canonical melanin biosynthesis pathway protects Aspergillus terreus conidia from environmental stress, Cell Chem. Biol. 23 (2016) 587-597.

[12] R. Prados-Rosales, S. Toriola, A. Nakouzi, S. Chatterjee, R. Stark, G. Gerfen, P. Tumpowsky, E. Dadachova, A. Casadevall, Structural characterization of melanin pigments from commercial preparations of the edible mushroom Auricularia auricula, J. Agric. Food. Chem. 63 (2015) 7326-7332.

[13] Y. Zou, W. Hu, K. Ma, M. Tian, Physicochemical properties and antioxidant activities of melanin and fractions from Auricularia auricula fruiting bodies, Food. Sci. Biotechnol. 24 (2015) 15.

[14] B.M. Bashyal, R. Chand, C. Kushwaha, D. Sen, L.C. Prasad, A.K. Joshi, Association of melanin content with conidiogenesis in Bipolaris sorokiniana of barley (Hordeum vulgare L.), World. J. Microbiol. Biotechnol. 26 (2010) 309-316.

[15] R. Chand, M. Kumar, C. Kushwaha, K. Shah, A.K. Joshi, Role of melanin in release of extracellular enzymes and selection of aggressive isolates of Bipolaris sorokiniana in barley, Curr. Microbiol. 69 (2014) 202-211.

[16] C.W. Fernandez, R.T. Koide, The function of melanin in the ectomycorrhizal fungus Cenococcum geophilum under water stress, Fungal Ecol. 6 (2013) 479-486.

[17] R.T. Koide, C. Fernandez, G. Malcolm, Determining place andprocess: functional traits of ectomycorrhizal fungi that affect both community structure and ecosystem function, New Phytol. 201 (2014) 433-439.

[18] C. Llorente, A. Bárcena, J. Vera Bahima, M.C.N. Saparrat, A.M. Arambarri, M.F. Rozas, M.V. Mirífico, P.A. Balatti, Cladosporium cladosporioides LPSC 1088 produces the 1,8-dihydroxynaphthalene-melanin-like compound and carries a putative pks gene, Mycopathologia 174 (2012) 397-408.

[19] Y. Wang, P. Aisen, A. Casadevall, Cryptococcus neoformans melanin and virulence: mechanism of action, Infect. Immun. 63 (1995) 3131-3136.

[20] R.J. Frandsen, S.A. Rasmussen, P.B. Knudsen, S. Uhlig, D. Petersen, E. Lysøe, C.H. Gotfredsen, H. Giese, T.O. Larsen, Black perithecial pigmentation in Fusarium species is dueto the accumulation of 5-deoxybostrycoidin-based melanin, Sci. Rep. 6 (2016) 26206.

21] M.N. Tseng, C.L. Chung, S.S. Tzean, Mechanisms relevant to the enhanced virulence of a dihydroxynaphthalene-melanin metabolically engineered entomopathogen, PLoS One 9 (2014) e90473.

[22] M. Villarino, P. Sandín-España, P. Melgarejo, A. De Cal, High chlorogenic and neochlorogenic acid levels in immature peaches reduce Monilinialaxa infection by interfering with fungal melanin biosynthesis, J. Agric. Food. Chem. 59 (2011) 3205-3213.

[23] M. Orlowski, Mucor dimorphism, Microbiol. Rev. 55 (1991) 234-258.

[24] D.A. Wubah, M.S. Fuller, D.E. Akin, Resistant body formation in Neocallimastix sp., an anaerobic fungus from the rumen of a cow, Mycologia 83 (1991) 40-47.

[25] C. Dong, Y. Yao, Isolation, characterization of melanin derived from Ophiocordyceps sinensis, an entomogenous fungus endemic to the Tibetan Plateau, J. Biosci. Bioeng. 113 (2012) 474-479.

[26] A. Vasanthakumar, A. DeAraujo, J. Mazurek, M. Schilling, R. Mitchell, Pyomelanin production in Penicillium chrysogenum is stimulated by L-tyrosine, Microbiology 161 (2015) 1211-1218.

[27] M.C.N. Saparrat, G. Fermoselle, S. Stenglein, M. Aulicino, P.A. Balatti, Pseudocercospora griseola causing angular leaf spot on Phaseolus vulgaris produces 1,8-dihydroxynaphthalene-melanin, Mycopathologia 168 (2009) 41-47.

[28] R. Almeida-Paes, S. Frases, P.C. Fialho-Monteiro, M.C. Gutierrez-Galhardo R.M. Zancopé-Oliveira, J.D. Nosanchuk, Growth conditions influence melanization of Brazilian clinical Sporothrix schenckii isolates, Microbes Infect. 11 (2009) 554-562.

[29] R. Almeida-Paes, S. Frases, G. de S. Araujo, M.M. de Oliveira, G.J. Gerfen, J.D. Nosanchuk, R.M. Zancopé-Oliveira, Biosynthesis and functions of a melanoid pigment produced by species of the Sporothrix complex in the presence of L-tyrosine, Appl. Environ. Microbiol. 78 (2012) 8623-8630.

[30] R. Almeida-Paes, M.H.G. Figueiredo-Carvalho, F. Brito-Santos, F. Almeida-Silva, M.M.E. Oliveira, R.M. Zancopé-Oliveira, Melanins protect Sporothrix brasiliensis and Sporothrix schenckii from the antifungal effects of Terbinafine, PLoS One 11 (2016) e0152796.

[31] M.C. Hampson, R. Amarowicz, F. Shahidi, The presence of melanin in Synchytrium endobioticum, Mycologia 4 (1996) 647-650.

[32] M.C. Saparrat, M.N. Cabello, A.M. Arambarri, Extracellular laccase activity in Tetraploa aristata, Biotechnol. Lett. 24 (2002) 1375-1377.

[33] A.A. Bell, M.H. Wheeler, Biosynthesis and functions of fungal melanins, Annu. Rev. Phytopathol. 24 (1986) 411-451.

[34] E. Sansinenea, A. Ortiz, Melanin: a photoprotection for Bacillus thuringiensis based biopesticides, Biotechnol. Lett. 37 (2015) 483-490.

[35] M. Pihet, P. Vandeputte, G. Tronchin, G. Renier, P. Saulnier, S. Georgeault R. Mallet, D. Chabasse, F. Symoens, J.P. Bouchara, Melanin is an essential component for the integrity of the cell wall of Aspergillus fumigatus conidia BMC Microbiol. 9 (2009) 177.

[36] C.H. Eisenman, A. Casadevall, Synthesis and assembly of fungal melanin, Appl Microbiol. Biotechnol. 93 (2012) 931-940.

[37] E. Dadachova, R.A. Bryan, X. Huang, T. Moadel, A.D. Schweitzer, P. Aisen, J.D. Nosanchuk, A. Casadevall, Ionizing radiation changes the electronic properties of melanin and enhances the growth of melanized fungi, PLoS One (2007) e457. 